\title{
The Use of Systemic Lupus Erythematosis (SLE) Biomarkers in Forensic Investigation: A Suggested Approach
}

Hossam A Eid

Department of Oral medicine \& Periodontology, Faculty of Dentistry, Suez Canal University, Ismailia, Egypt

*Corresponding author: Hossam A Eid, Department of Oral medicine \& Periodontology, Faculty of Dentistry, Suez Canal University, Ismailia, Egypt, Tel: 966530834985; E-mail: hosam@kku.edu.sa

Received date: Feb 08, 2014, Accepted date: Apr 01, 2014, Published date: April 05, 2014

Copyright: (02014 Eid HA This is an open-access article distributed under the terms of the Creative Commons Attribution License, which permits unrestricted use, distribution, and reproduction in any medium, provided the original author and source are credited.

\begin{abstract}
Forensic investigations usually depends on collecting clues, evidences and references. Long time ago, gene banks and finger prints have found their application in forensic analysis of crimes and for identification of individuals in mass disasters. Teeth and oral tissues were also included before. Recent studies used the characteristics DNA extracted from teeth remains to identify totally- deteriorated bodies. This article direct the attention toward the possibility of using diseases-associated biomarkers as a provisional tool for identifying individuals located in complicated forensic challenges. Systemic Lupus erythematosis (SLE) is one among the diseases that associated with the release of different biomarkers in body fluids. These biomarkers could help a differential identification of individuals at acceptable level of validity, however a disease-related biomarker banks should be established first.
\end{abstract}

Keywords: Biomarkers; Forensic investigation; Systemic lupus erythematosis; Autoimmune diseases; Adiponectin

\section{Background}

The oral cavity is a mirror reflecting the existing illness of different human body parts. A wide number of dermatological conditions can be manifested orally [1]. Dermatoses have frequently been reported with different frequencies in the oral cavity [1]. One of the most important concerns about systemic lupus erythematosis (SLE) is the presence of oral lesions, which is one of its diagnostic criteria [2]. In many cases, mucosal ulcers are the earliest manifestation of SLE that probably identify the disease. Khatibi et al. [2], proved that 102 out of 188 SLE Iranian patients (54.3\%) had oral lesions, where both buccal and labial ulcers were the most prevalent (28.1\%) [2].

SLE is a chronic autoimmune disorder of the connective tissue and blood vessels. With the active disease usually demonstrates antinuclear antibodies (ANA) and anti-double strand DNA (Anti-dsDNA) autoantibodies aganist various components of cell nucleus leading to inflammation, vasculitis and immune complex deposition [3]. The immune complex deposition along with complement activation could be the cause of lupus nephritis, that frequently accompanied with hypocomplementemia [4].

The exact etiology of SLE is still unclear, although multifactorial interaction with genetic and environmental factors has been implicated. Children and adolescents represent 15-20\% of all SLE patients [3] however its frequencies differ among racial and ethnic groups [5-7]. The overall prevalence of SLE- affected individuals in the general population is 1 in 2000 with a predilection for women $[5,8]$. The possibilities of using diseases' biomarkers have not hitherto been applied in forensic analysis. Therefore, this article aims to suggest below some practical implications of SLE-associated biomarkers that may help characterizing individuals:

Adipocytokines (adiponectin) are soluble mediators derived mainly from adipocytes and are thought to play an important role in both inflammatory and immunity processes [9]. Adiponectin normally show a strong genetic references, with an additive genetic heritability of $46 \%$ [10]. The ADIPOQ gene consists of three exons and two introns spanning a $17-\mathrm{kb}$ region and has been located on chromosome $3 q 27[10,11]$. The ADIPOQ gene was found to be the only major gene responsible for plasma adiponectin [12-15].

Different adiponectin levels were found to increasing the risk toward type 2 diabetes, atherosclerosis, coronary artery disease, and SLE too $[9,10]$. Some researchers [10] recently discovered low adiponectin leveles in plasma of obese individuals suffering from type 2 diabetes, hypertension, atherosclerosis or other diseases [10]. However, persons having SLE, diabetic nephropathy, and chronic renal failure showed higher levels of both plasma and urine adiponectin levels $[11,12]$.

Immuno-senescence is a normal biological process that occurs in all organisms involving marked decline in cell functions. These alterations make elderly individuals not only prone to infectious diseases but also malignancy and autoimmunity [16]. Those changes were reported to occur in the immune system during aging affect the onset of autoimmune diseases (ADs). This is due to the fact that aging is related to increased reactivity to self-antigens and loss of tolerance. Elderly people usually experience general systemic inflammation and aggravate degenerative diseases [17], which in turn, increase the risk of developing ADs due to telomere length alteration leading to rheumatic arthritis, scleroderma and SLE [18-23].

Moreover, anti-dsDNA autoantibodies are usually detected before clinical symptoms of SLE show up, [24,25] and are implicated in the pathogenesis of lupus nephritis which is the major cause of morbidity and mortality in SLE $[26,27]$. Referring to its high specificity, antidsDNA autoantibody production is one of SLE eleven classification criteria developed by the American College of Rheumatology (ACR) $[28,29]$. Men with SLE are more likely to have disability, hypertension, thrombosis, and renal, hematological, and serological manifestations than women. The end organs' damage and death are also more frequent in men [30]. On the other hand, women with SLE used to 
experience malar rash, photosensitivity, oral ulcers, alopecia, Raynaud's phenomenon and arthralgia [31]. Drug-induced lupus erythematosus (DI-LE) can develop clinical and immunopathological symptoms similar to idiopathic lupus in patients with no prior history of the disease [32]. All DI-LE symptoms normally resolved after discontinuation of the offending drug and relapse after re-exposure. The first case of DI-LE was described in 1945 [33] and its estimated incidence is almost $10 \%$ out of LE identified cases. Many antihypertensive preparations could provoke LE, [34,35] and the tumor necrosis factor-antagonists were additionally reported [36-38].

\section{Conclusion}

Depending on the aforementioned literature, the following conclusion could be deduced; the use of SLE-associated markers probably help the provisional identification of individuals when the implication of routine forensic approaches is challenging, but establishing diseases-associated biomarkers' bank is mandatory.

\section{Acknowledgement}

Author would like to express his sincere gratitude and appreciation to Dr. Khalid M. Abdelaziz, Associate Professor and Deputy chairman, scientific and research committee, College of Dentistry, King Khalid University, Abha, KSA for the help provided at the time of writing this article.

\section{References}

1. Roy S, Varshney S (2013) Oral dermatological conditions: a clinical study. Indian J Otolaryngol Head Neck Surg 65: 97-101.

2. Khatibi M, Shakoorpour AH, Jahromi ZM, Ahmadzadeh A (2012) The prevalence of oral mucosal lesions and related factors in 188 patients with systemic lupus erythematosus. Lupus 21: 1312-1315.

3. Mok CC, Lau CS (2003) Pathogenesis of systemic lupus erythematosus. J Clin Pathol 56: 481-490.

4. Stichweh D, Arce E, Pascual V (2004) Update on pediatric systemic lupus erythematosus. Curr Opin Rheumatol 16: 577-587.

5. Kone-Paut I, Piram M, Guillaume S, Tran TA (2007) Lupus in adolescence. Lupus 16: 606-612.

6. Shapira Y, Weinberger A, Wysenbeek AJ (1996) Lymphadenopathy in systemic lupus erythematosus. Prevalence and relation to disease manifestations. Clin Rheumatol 15: 335-338.

7. Rahman A, Isenberg DA (2008) Systemic lupus erythematosus. N Engl J Med 358: 929-939.

8. Wang J, Yang S, Chen JJ, Zhou SM, He SM, et al. (2007) Systemic lupus erythematosus: a genetic epidemiology study of 695 patients from China. Arch Dermatol Res 298: 485-491.

9. Pisetsky D (2001) Systemic Lupus Erythematosus: Epidemiology, Pathology, and Pathogenesis. In: Klippel J ed. Primer of the Rheumatic Diseases. (12th edn). Atlanta: Arthritis Foundation.

10. Chung CP, Long AG, Solus JF, Rho YH, Oeser A, et al. (2009) Adipocytokines in systemic lupus erythematosus: relationship to inflammation, insulin resistance and coronary atherosclerosis. Lupus 18: 799-806.

11. Rovin BH, Song H, Hebert LA, Nadasdy T, Nadasdy G, et al. (2005) Plasma, urine, and renal expression of adiponectin in human systemic lupus erythematosus. Kidney Int 68: 1825-1833.

12. Rovin BH1, Birmingham DJ, Nagaraja HN, Yu CY, Hebert LA (2007) Biomarker discovery in human SLE nephritis. Bull NYU Hosp Jt Dis 65: 187-193.

13. Adamczak M, Wiecek A, Funahashi T, Chudek J, Kokot F, et al. (2003) Decreased plasma adiponectin concentration in patients with essential hypertension. Am J Hypertens 16: 72-75.
14. Zoccali C, Mallamaci F, Tripepi G, Benedetto FA, Cutrupi S, et al. (2002) Adiponectin, metabolic risk factors, and cardiovascular events among patients with end-stage renal disease. J Am Soc Nephrol 13: 134-141.

15. Comuzzie AG, Funahashi T, Sonnenberg G, Martin LJ, Jacob HJ, et al. (2001) The genetic basis of plasma variation in adiponectin, a global endophenotype for obesity and the metabolic syndrome. J Clin Endocrinol Metab 86: 4321-4325.

16. Takahashi M, Arita Y, Yamagata K, Matsukawa Y, Okutomi K, et al. (2000) Genomic structure and mutations in adipose-specific gene, adiponectin. Int J Obes Relat Metab Disord 24: 861-868.

17. Ouchi N, Kihara S, Arita Y, Maeda K, Kuriyama H, et al. (1999) Novel modulator for endothelial adhesion molecules: adipocyte-derived plasma protein adiponectin. Circulation 100: 2473-2476.

18. Kawano J, Arora R (2009) The role of adiponectin in obesity, diabetes, and cardiovascular disease. J Cardiometab Syndr 4: 44-49.

19. Li S, Shin HJ, Ding EL, van Dam RM (2009) Adiponectin levels and risk of type 2 diabetes: a systematic review and meta-analysis. JAMA 302: 179-188.

20. Heid IM, Henneman P, Hicks A, Coassin S, Winkler T, et al. (2010) Clear detection of ADIPOQ locus as the major gene for plasma adiponectin: results of genome-wide association analyses including 4659 European individuals. Atherosclerosis 208: 412- 420 .

21. Franceschi C, Capri M, Monti D, Giunta S, Olivieri F, et al. (2007) Inflammaging and anti-inflammaging: a systemic perspective on aging and longevity emerged from studies in humans. Mech Ageing Dev 128: 92-105.

22. Mohan SV Liao YJ, Kim JW, Goronzy JJ, Weyand CM (2011) Giant cell arteritis: immune and vascular aging as disease risk factors. Arthritis Res Ther 13: 231.

23. Goronzy JJ, Shao L, Weyand CM (2010) Immune aging and rheumatoid arthritis. Rheum Dis Clin North Am 36: 297-310.

24. Schönland SO, Lopez C, Widmann T, Zimmer J, Bryl E, et al. (2003) Premature telomeric loss in rheumatoid arthritis is genetically determined and involves both myeloid and lymphoid cell lineages. Proc Natl Acad Sci U S A 100: 13471-13476.

25. Artlett CM, Black CM, Briggs DC, Stevens CO, Welsh KI (1996) Telomere reduction in scleroderma patients: a possible cause for chromosomal instability. Br J Rheumatol 35: 732-737.

26. Honda M, Mengesha E, Albano S, Nichols WS, Wallace DJ, et al. (2001) Telomere shortening and decreased replicative potential, contrasted by continued proliferation of telomerase-positive CD8+ CD28(lo)T cells in patients with systemic lupus erythematosus. Clinical Immunology 99: 211-221.

27. Vogt S, Iking-Konert C, Hug F, Andrassy K, Hänsch GM (2003) Shortening of telomeres: Evidence for replicative senescence of T cells derived from patients with Wegener's granulomatosis. Kidney Int 63: 2144-2151.

28. Wu K, Higashi N, Hansen ER, Lund M, Bang K, et al. (2000) Telomerase activity is increased and telomere length shortened in T cells from blood of patients with atopic dermatitis and psoriasis. J Immunol 165: 4742-4747.

29. Gladis Montoya-Ortiz (2013) Immunosenescence, Aging, and Systemic Lupus Erythematous. Hindawi Publishing Corporation. Autoimmune Diseases : 15 .

30. Tan TC, Fang H, Magder LS, Petri MA (2012) Differences between male and female systemic lupus erythematosus in a multiethnic population. J Rheumatol 39: 759-769.

31. Chung SA, Taylor KE, Graham RR, Nititham J, Lee AT, et al. (2011) Differential genetic associations for systemic lupus erythematosus based on anti-dsDNA autoantibody production. PLoS Genet 7: e1001323.

32. Buyon J (2008) Systemic Lupus Erythematosus: A. Clinical and Laboratory Features. In: Klippel J, ed. Primer on the Rheumatic Diseases. (13th edn). New York NY: Springer: 303-318.

33. Hoffman BJ (1945) Sensitivity to sulfadiazine resembling acute disseminated lupus erythematosus. Arch Derm Syphilol 51:190-192. 
Citation: Hossam A Eid (2014) The Use of Systemic Lupus Erythematosis (SLE) Biomarkers in Forensic Investigation: A Suggested Approach. J Forensic Res S: S12-003. doi:10.4172/2157-7145.S12-003

Page 3 of 3

34. Isenberg DA, Manson JJ, Ehrenstein MR, Rahman A (2007) Fifty years of anti-ds DNA antibodies: are we approaching journey's end? Rheumatology (Oxford) 46: 1052-1056.

35. Tan EM, Cohen AS, Fries JF, Masi AT, McShane DJ, et al. (1982) The 1982 revised criteria for the classification of systemic lupus erythematosus. Arthritis Rheum 25: 1271-1277.

36. Hochberg MC (1997) Updating the American College of Rheumatology revised criteria for the classification of systemic lupus erythematosus. Arthritis Rheum 40: 1725 .
37. Gateva V, Sandling JK, Hom G, Taylor KE, Chung SA, et al. (2009) A large-scale replication study identifies TNIP1, PRDM1, JAZF1, UHRF1BP1 and IL10 as risk loci for systemic lupus erythematosus. Nat Genet 41: 1228-1233.

38. Marzano AV, Vezzoli P, Crosti C (2009) Drug-induced lupus: an update on its dermatologic aspects. Lupus 18: 935-940. 